\title{
Culex (Culex) interfor Dyar (Diptera: Culicidae), Morphological Description Including Previously Unknown Life Stages
}

\author{
Maria Anice Mureb Sallum, Walter Ricardo Almirón**, \\ Oswaldo Paulo Forattini*/+
}

\begin{abstract}
Núcleo de Pesquisa Taxonômica e Sistemática em Entomologia Médica (NUPTEM) *Departamento de Epidemiologia, Faculdade de Saúde Pública, Universidade de São Paulo, Av. Dr. Arnaldo 715, 01246-904 São Paulo, SP, Brasil **Centro de Investigaciones Entomologicas de Córdoba, Facultad de Ciencias Exactas, Físicas y Naturales, Universidad Nacional de Córdoba, Av. Vélez Sarsfield 299(5000) Córdoba, Argentina
\end{abstract}

The adult female and male and the pupal and larval stages of Culex (Culex) interfor Dyar are described and compared with those of $\mathrm{Cx}$. bidens Dyar. Available data about distribution are presented.

Key words: Culex interfor - Diptera - Culicidae

Culex (Culex) interfor was described by Dyar (1928). Bram (1967) synonymized $C x$. interfor with $C x$. bidens Dyar, 1922 based on superficial similarities in the male genitalia. Harbach et al. (1986) resurrected $C x$. interfor from synonymy based on a careful study of male genitalia. The shape of the ventral arm and the dentition of the lateral plate of the phallosome are important features which distinguish these species.

During ecological studies carried out in Córdoba, Argentina, one of the authors (WR Almirón) collected and reared immature stages of $C x$. interfor, obtaining adults associated with immature stages. These specimens enabled us to describe the adults and immature stages of this species. The larval and pupal stages were unknown until now.

\section{TAXONOMIC TREATMENT}

\section{Culex (Culex) interfor Dyar}

Culex (Culex) interfor Dyar, 1928: 372 ( Ơ,Q). Lectotype male: between Tucumán and Jujuy, Argentina (NMNH); Lane 1953: 346 $\left(O^{*}, Q\right)$; Stone and Knight 1957:51 (lectotype desig.); Bram 1967: 35 (syn. with $C x$. bidens Dyar); Harbach et al. 1986: 141 (G $\sigma^{*}$; resurrected from syn.).

\footnotetext{
Partially supported by Fundação de Amparo à Pesquisa do Estado de São Paulo(FAPESP)(Grant no 93/3349-9). ${ }^{+}$Corresponding author. Fax: 55-11-282.1898

Received 9 November 1995

Accepted 29 March 1996
}

FEMALE. Head: proboscis dark-scaled, frequently with pale scaling on ventral surface from base to 0.75 length. Maxillary palpus entirely darkscaled. Antennal pedicel without scales, yellowish, but light brown on medial portion; base of first flagellomere yellowish, remainder dark. Vertex mostly with narrow decumbent scales, these white posteriorly and on ocular line, light tanned anteriorly; a small patch of broad dingy white scales on postgena; forked scales light brown; occipital region with narrow white scales. Cibarial armature (Fig. 1D,E): cibarial bar concave, dorsal surface and posterior margin smooth; about 24-26 small, spatulate teeth, each tooth more expanded on distal part, apical margin smooth, truncate; hollow area absent. Thorax (Fig. 1C): integument light brown, scutum covered with very fine falcate scales, background scales mostly coppery with golden reflections, with some whitish scales on anterior promontory and supraalar and prescutellar areas. Scutal setae prominent, brown with golden or reddish reflections; acrostichal setae present. Scutellar scales white; lateral lobes each with 4-6 large setae, median lobe with 5-8 long setae. Antepronotum with scattered narrow dingy white scales and with brown setae over most of surface. Postpronotum with narrow brown scales along dorsal margin; posterolateral margin with dark setae. Proepimeron bare. Upper proepisternum with numerous setae and a patch of broad white scales. Lower mesokatepisternum with 1-5 setae and a patch of broad white scales; upper mesokatepisternum with a row of setae and a patch of broad white scales on upper corner. Mesepimeron with 1 lower seta, 4-6 upper setae and patches of broad white scales on anterior and upper portions. Paratergite without scales. Pleural integument yellowish, darker on postpronotum, 
postspiracular area, subspiracular area and prealar knob, a dark spot on mesokatepisternum between the 2 patches of white scales, spot extends to the anterior area of mesepimeron and onto upper mesepimeron. Legs: dark-scaled, scales similar in color to proboscis. Forecoxa with a small patch of light scales dorsally, dark scales ventrally and anteriorly, mid- and hindcoxae with longitudinal patches of colorless scales. Femora dark-scaled except for usual pale scales and small patch of pale scales at apex. Fore-, mid- and hindtibiae dark dorsally, pale ventrally. Foretarsus mostly dark-scaled with indistinct patches of pale scales on base of foretarsomeres 2-4, 5 dark; midtarsus similar to foretarsus; hindtarsomere 1 dark dorsally, pale ventrally, 2-5 with inconspicuous patches of pale scales at base. Wing (Fig. 1A,B): scales dark brown, sometimes with a few pale scales on basal portion of costa, reaching humeral cross-vein. Abdomen: tergum I with a median posterior patch of dark scales; terga II-VII dark-scaled with basolateral patches of white scales; tergum II, occasionally with small median anterior patch of white scales; terga III-VII sometimes with narrow anterior bands of white scales; tergum VIII white-scaled anteriorly, dark posteriorly. Sterna white-scaled, occasionally with a few scattered dark scales.

MALE. Like female except for the following sexual differences. Head: antenna strongly verticilate. Maxillary palpus longer than proboscis; entirely dark brown on dorsal surface, ventral surface with patches of white scales on base of palpomere 5, from apex to base of 4 and just beyond middle of 3; palpomeres 4 and 5 densely setose along ventral surface, palpomere 3 with strong setae on outer area just beyond middle. Abdomen: tergum II entirely dark-scaled or with a median anterior patch of white scales; terga III-VI darkscaled with narrow anterior bands of white scales (remaining terga removed with genitalia). Sternum II white-scaled; sterna III-VI variable, mostly white-scaled or, sometimes, covered with light brown scales and narrow anterior bands of white scales and a few white scales posteriorly. Genitalia: consult Harbach et al. (1986).

PUPA (Fig. 2). Placement and character of setae as figured; range and modal number of branches in Table I. Cephalothorax: lightly tanned, scutum, postscutal area, dorsal portion of mesothoracic wing, metanotum, metathoracic wing and legs darker. Setae 1,4-CT usually triple; $2,5,8,12-\mathrm{CT}$ usually with 4 branches, 5,12-CT with 4,5 branches; 3,6,9,11-CT usually double, 6,11-CT with 2,3 branches; 10-CT often with 6 branches (6-13). Trumpet: moderately tanned, cylindrical; index 4.41-7.15 $(\bar{X}=5.82)$; tracheoid area darker, extending about 0.46 from base. Abdomen: lightly tanned, posteromedian portion of tergum I darkly pigmented, anterior margins of terga darker, particularly on terga II-IV, surface of sternum I with tiny spicules; length $2.05-2.51 \mathrm{~mm}(\bar{X}=2.35 \mathrm{~mm})$. Seta 6-I,II normally single; 7-I always double, 7-II most often double (2,3); 1-II with 16-21 branches; 1-III usually with 7 branches, 1-IV often with 6 branches, 1-V usually triple; 2 -II lateral to seta 1, 2-III-VI mesal to 1, 2-VII variable in position, lateral or mesal to 1 ; 5-IV usually triple (2-4), 5-VVII usually double; 6-III usually double $(2,3), 6$ IV-VI normally double. Genital lobe: lightly tanned in female, darker in male; length about $0.16 \mathrm{~mm}$ in female, $0.25 \mathrm{~mm}$ in male. Paddle: lightly tanned, outer margin with minute spicules from base to 0.6 length; midrib distinct except at apex; seta 2-P present, about 0.5 length of 1-P.

LARVA (Fig. 3). Placement and character of setae as figured; range and modal number of branches in Table II. Head: wider than long; length and width not measured; lightly tanned, anterior part of dorsal apotome slightly darker, posterior part of dorsal apotome and posterior part of lateralia with moderately tanned spots. Median labral plate narrow but distinct. Labiogula narrower anteriorly than posteriorly; hypostomal suture complete, extended posterolaterally from posterior tentorial pit to near collar. Collar moderately developed along lateralia, heavily tanned. Dorsomentum with 7-10 teeth on either side of median tooth. Seta 1-C slender, lightly tanned; 2-C absent; 3-C distinct; 4-C slender, single; 5,6-C strongly developed, 5-C with $2-4$ branches, 6-C usually triple $(2,3)$; 7-C resembles 5,6-C, with 5-10 branches; 8-C with 3-5 branches; 9-C with 3-9 branches; $10-\mathrm{C}$ with 3-5 branches; $11-\mathrm{C}$ usually triple; $12-\mathrm{C}$ usually with 5 branches; $13-\mathrm{C}$ usually with 4 branches; $14-\mathrm{C}$ most often single (1-3); 15-C with 3-8 branches; 16,17$\mathrm{C}$ absent. Antenna: length $0.45-0.51 \mathrm{~mm}(\overline{\mathrm{X}}=$ $0.48 \mathrm{~mm}$ ), lightly tanned, mesal surface with dark spot at base, portion distal to seta 1-A darker, or evenly and moderately tanned with a dark spot at base of mesal surface; seta 1-A 0.29-0.36 from base; antennal flagellum proximal to seta 1-A, aciculate, distal part thinner and with a few aciculae laterally near seta 1-A. Seta 1-A large, with 22-30 aciculate branches. Thorax: integument hyaline, covered with tiny spicules; tubercles of all large setae moderately tanned; tubercles of setae 9-12 without spine on prothorax, but with moderately large spines on meso- and metathorax. Setae 1-3$\mathrm{P}$ single, nearly of equal length; 4-P normally double; 7,8-P usually double (2,3), 7-P with 2,3 branches, 8-P with 1-3 branches; 11-P with 5-9 branches. Seta 1-M usually single (1-3), shorter 

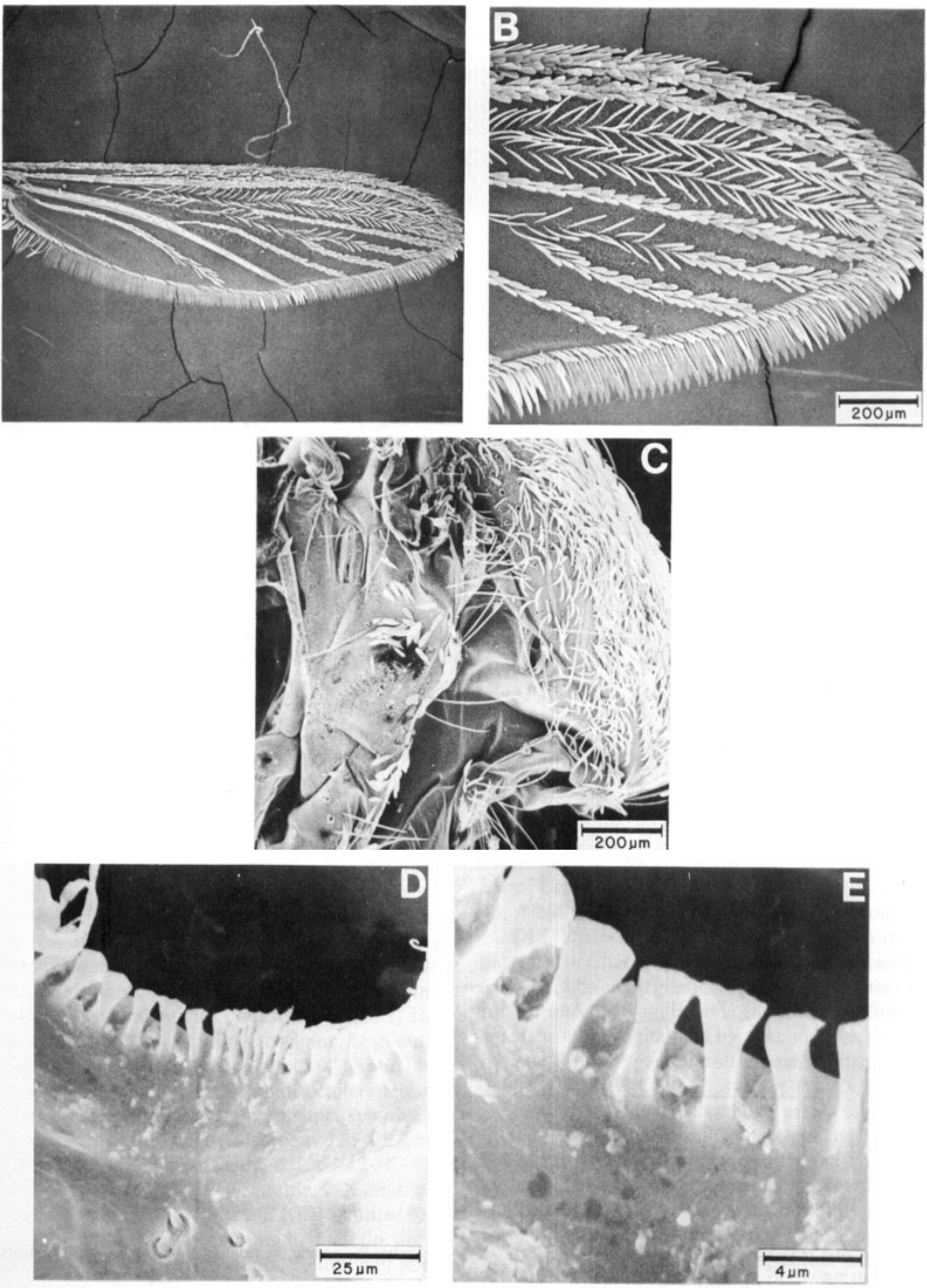

Fig. 1: Culex (Cux.) interfor, female. A,B: dorsal surface of right wing; C: lateral aspect of thorax; D,E: cibarial armature. 


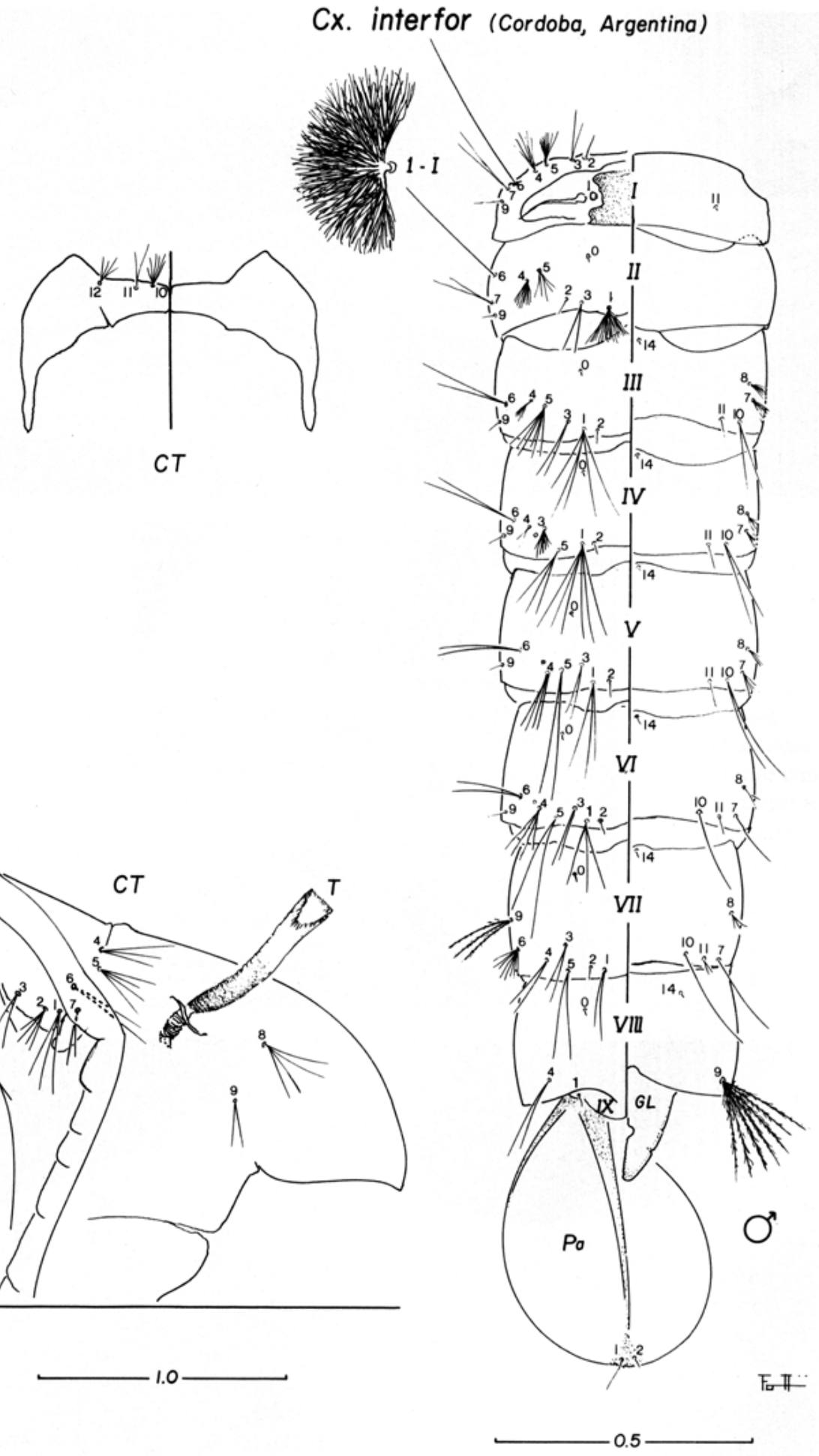

Fig. 2: Culex (Cux.) interfor, pupa. CT: cephalothorax; GL: genital lobe; Pa: paddle; T: trumpet; I-IX: abdominal segments. Scales in $\mathrm{mm}$.

than 3-M; 3-M normally single; 4-M always double. Seta $1-\mathrm{T}$ short, less than 0.5 of $2-\mathrm{T}$, with 2-4 branches; 2-T with 2,3 branches. Abdomen: integument hyaline, spiculation finer than on thorax, more evident on segment VIII; tubercles of setae 6-I-VI, 7-I and 1,3-VIII moderately tanned. 
TABLE I

Number of branches for setae of the pupa of Culex(Cux.)interfor ${ }^{a}$

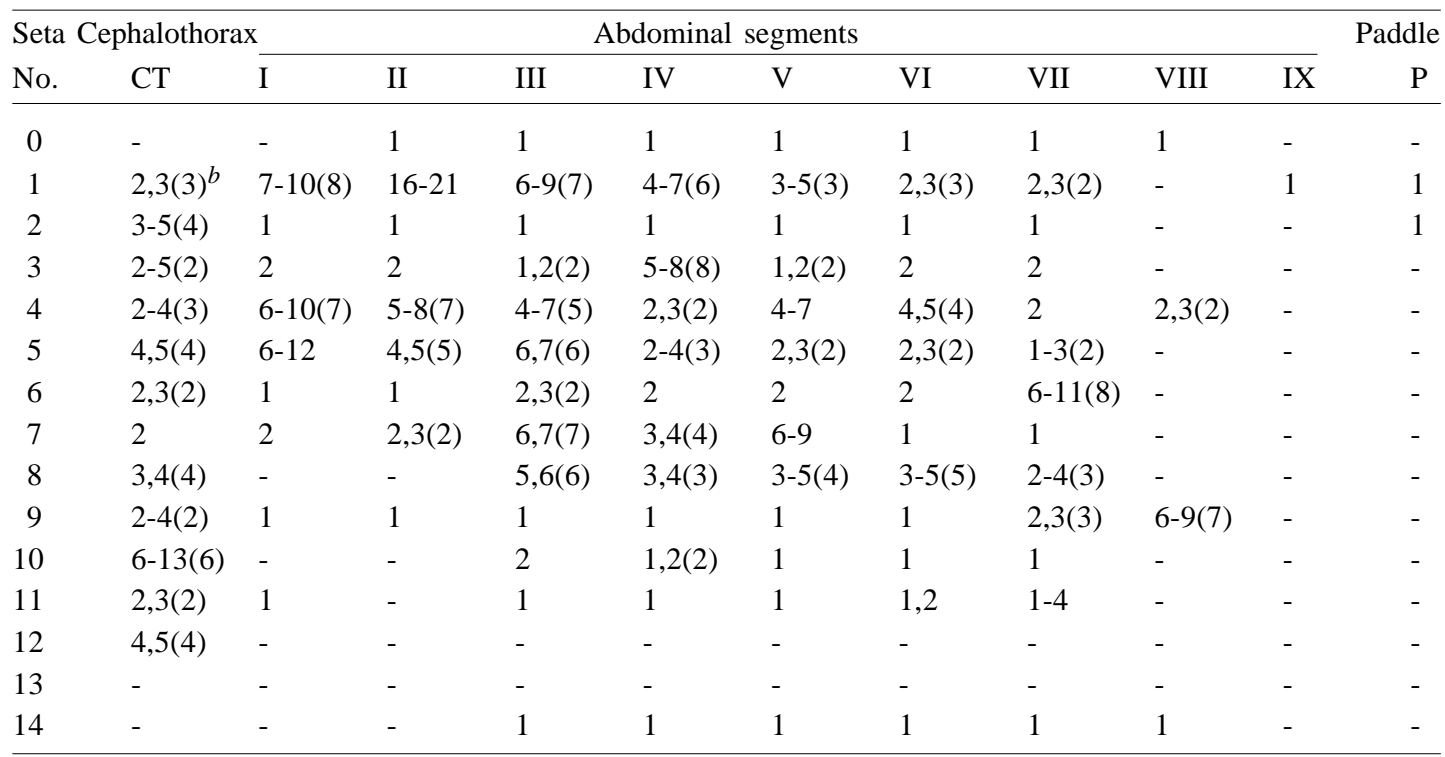

$a$ : based on counts made on 5 to 10 setae; $b$ : range (mode, when distinct).

Seta 3-I-VII most often single, 3-I,II,IV,V,VII occasionally double; 6-I-VI long, 6-I,II triple or with 4 branches, 6-III-VI normally double; 7-I similar to 6-I, usually double (1-3); 1-I with 3-8 branches, 1-II,IV,VI double or triple, 1-III usually triple, 1V,VII triple or with 4 branches. Segment VIII: comb with 24-44 scales; scales short, normally fringed on sides and apex, apical fringe more distinct; arranged in 4 irregular rows. Seta 1-VIII with 3-8 branches; 3-VIII with 6-10 branches; 5-VIII with 2-6 branches. Siphon: index 3.62-5.26 ( $\overline{\mathrm{X}}=4.49)$; moderately tanned, strongly tanned on acus, base, spiracular apparatus, spiracular apodeme and apex; mean spiracular apodeme ratio [length of spiracular apodeme divided by dorsal length of siphon (Strickman \& Pratt 1989)] 0.24. Pecten on basal 0.30 of siphon, with 12-15 spines; larger spines with 2-4 basal denticles. Seta 1-S in 3 pairs, $1 \mathrm{a}-\mathrm{S}$ inserted near most distal pecten spine, $1 \mathrm{~b}-\mathrm{S}$ out of line with the others, arising about 0.7 from 1a-S. Segment $X$ : saddle complete, moderately tanned, slightly darker dorsally, with distinct spicules on lateral area of posterior end; length $0.35-0.37 \mathrm{~mm}$ $(\overline{\mathrm{X}}=0.36 \mathrm{~mm})$, siphon/saddle index 3.42- $4.14(\overline{\mathrm{X}}$ $=3.82$ ). Seta $1-X$ single or double; $2-X$ double or triple; $4-X$ usually in 5 pairs. Anal papillae long and slender, gradually tapering to blunt tip, dorsal pair about 1.8 length of saddle, ventral pair about 1.5 length of saddle.

MATERIAL EXAMINED. $C x$. interfor: $80^{\circ}$, 13Q , 17 OG, $16 \mathrm{Pe}, 18 \mathrm{Le}$, as follows: ARGENTINA, Córdoba State, Ruta 36 y Río Segundo, 3
Mar. 1988, Almirón and Brewer coll. 2Q 10"3Pe 3Le 30'G; 8 Mar. 1989, 2Q 20' 4Pe 4Le 20'G; Alta Gracia, Puesto La Soledad, 26 Jan. 1988, Almirón coll. 1Q 1Pe 1Le 10 G; Puesto de Gonzáles, 3 Feb. 1987, Almirón and Brewer coll. 1Q1Pe 1Le; Colonia Caroya, 13 Feb. 1988, Almirón and Brewer coll. 1Q 10̛ 2Le 20̛'G; Campo Grande, 6 Dec. 1987, Almirón coll., 5Q 40 7Pe 7Le 9ƠG; Valle del Rosario, 29 Jan. 1987, Brewer coll., 1․ Cx. bidens: 5 Pe, 5 Le with associated males and females, as follows: BRAZIL, São Paulo State, Cesário Lange County, SP 141 Road, km 43, Aleluia District, 19 Mar. 1990, Sucen coll.

DISTRIBUTION. $C x$. interfor is known from the states of Chaco, Corrientes, Santa Fé, Tucumán and Córdoba in Argentina. Lane's (1953) record for $C x$. interfor from Bolivia cannot be confirmed since the male genitalia of his specimen are poorly mounted and the genitalic structures are damaged.

SYSTEMATICS. $C x$. interfor and $C x$. bidens are similar species which can be easily separated by the male genitalia and some characters of the larva and pupa. These species apparently cannot be recognized by the adult female. According to Harbach et al. (1986), Cx. interfor mainly differs from $C x$. bidens by having the lateral plate of phallosome with a single strong apical tooth, infrequently with 1 or 2 minute denticles and the ventral arm is uniquely developed as a small triangular flaplike process, directed laterally. In contrast, $C x$. bidens has the lateral plate with 1-3 large 


\section{Cx. interfor (Cordoba, Argentina)}

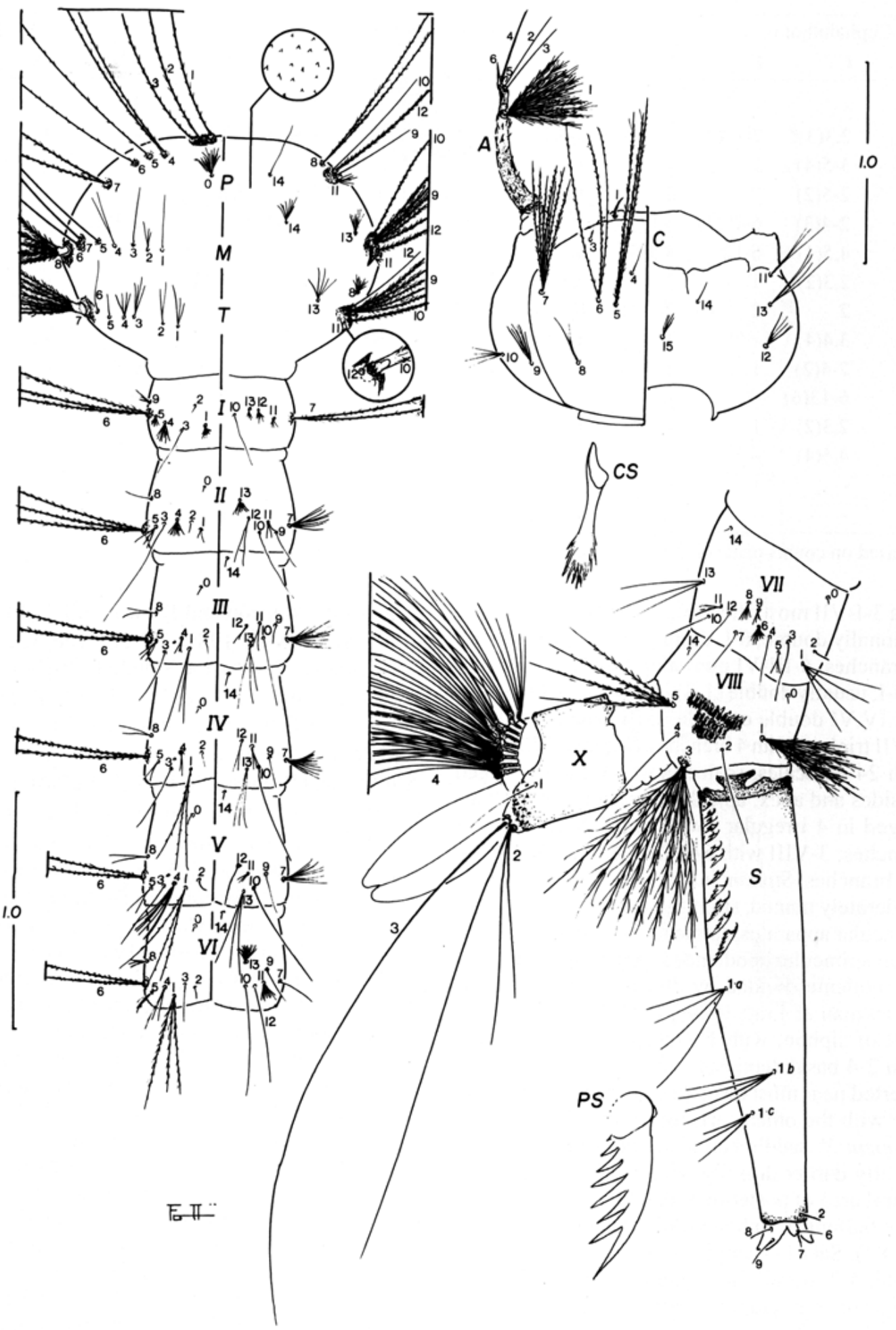

Fig. 3: Culex (Cux.) interfor, larva. A: antenna; C: cranium; CS: comb scale; M: mesothorax; P: prothorax; PS: pecten spine; S: siphon; T: metathorax; I-X: abdominal segments. Scales in $\mathrm{mm}$. 


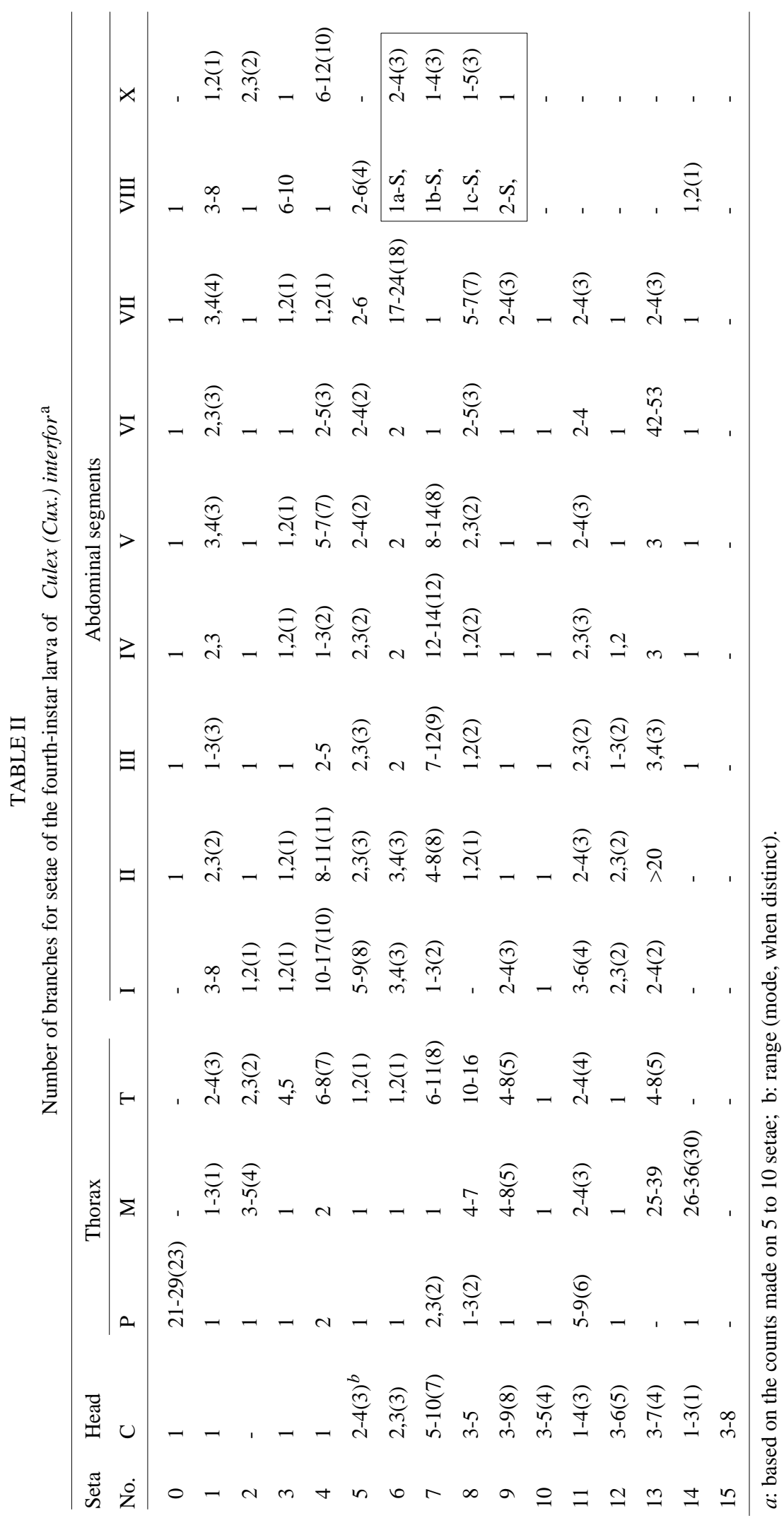


dorsolaterally directed teeth, 0-3 minute conical denticles and the ventral arm is strongly developed as a spine dorsolaterally bent.

In the larval stage, $C x$. interfor differs from $C x$. bidens in having seta 4-II with 8-11 branches, 7IV with 12-14 branches, 1-V triple or with 4 branches, $7-\mathrm{V}$ with $8-14$ branches. $C x$. bidens has seta 4-II with 4-9 branches, 7-IV with 7-9 branches, $1-\mathrm{V}$ normally double and 7-V with 6-9 branches. The position of seta 1a,b-S of siphon and the number of scales of the comb scales may be useful to separate these species. $C x$. interfor has $24-44$ comb scales and seta $1 \mathrm{~b}-\mathrm{S}$ arises about 0.7 from 1a-S. $C x$. bidens has $46-52$ comb scales and seta $1 \mathrm{~b}-\mathrm{S}$ arises about 0.5 from $1 \mathrm{a}-\mathrm{S}$.

In the pupal stage $C x$. interfor can be easily differentiated from $C x$. bidens by having setae 1II with 16-21 branches, 5-III with 6,7 branches, 7$\mathrm{V}$ with 6-9 branches, 4-VI with 4,5 branches and 6-VII with 6-11 branches. The character of the trumpet can be used to distinguish these species. In $C x$. interfor the trumpet is moderately tanned and the mean trumpet index 5.82. In $C x$. bidens the trumpet is darker than in $C x$. interfor and the mean trumpet index 7.41.

$C x$. interfor can be distinguished from the other species of the subgenus Culex in the New World by adding the following modification to the key constructed by Bram (1967). The terms used by Bram for some morphological features have been changed to agree with Harbach and Knight (1980):

20.(19) Seta 6-C with 4,5 branches; siphonal saddle index about 3.5... mollis Seta 6-C usually triple; siphonal saddle index $3.42-4.14$.
21.(20) Setae 4-II, 7-IV, 1-V, 7-V with 8-11,12$14,3-4,8-14$ branches, respectively; comb with 24-44 scales, siphon with seta $1 \mathrm{~b}-\mathrm{S}$ arising about 0.7 from $1 \mathrm{a}-\mathrm{S}$...interfor Setae 4-II, 7-IV, 1-V 7-V with 4-9, 7-9, 2, 6-9 branches, respectively; comb with 46-56 scales; siphon with seta $1 \mathrm{~b}-\mathrm{S}$ arising about 0.5 from $1 \mathrm{a}-\mathrm{S}$. ...bidens

\section{ACKNOWLEDGMENTS}

To Dr Ralph E Harbach (Natural History Museum, London, UK) and Dr Ricardo Lourenço-de-Oliveira (Instituto Oswaldo Cruz, Rio de Janeiro, Brazil) for valuable comments and suggestions.

\section{REFERENCES}

Bram RA 1967. Classification of Culex subgenus Culex in the New World (Diptera, Culicidae). Proc US Nat Hist Mus 120: 1-122.

Dyar HG 1928. The mosquitoes of Americas. Carnegie Inst. Wash. Washington D.C., Publ. No 387, 616 pp.

Harbach RE, Knight KL 1980. Taxonomists' glossary of mosquito anatomy. Plexus Publishing, Inc., Marlton, New Jersey, 413 pp.

Harbach RE, Jakob WL, Peyton EL 1986. Recognition of Culex bidens Dyar and Culex interfor Dyar (Diptera, Culicidae) as separate species. Mosq Syst 18: 139-144.

Lane J 1953. Neotropical Culicidae. Ed. USP, São Paulo, Brazil, 1112 pp.

Stone A, Knight KL 1957. Type specimens of mosquitoes in the United States National Museum: IV, The genus Culex (Diptera, Culicidae). J Wash Acad Sci 47: 42-59.

Strickman D, Pratt J 1989. Redescription of Culex corniger Theobald and elevation of Culex (Culex) lactator Dyar and Knab from synonymy based on specimens from Central America (Diptera: Culicidae). Proc Entomol Soc Wash 91: 551-574. 